\title{
On Developing an Open Courseware Organization Mechanism for China' Higher Education Institutions
}

\author{
Heqi Wang ${ }^{1, a}$, Guanlin Wu ${ }^{2, b}, Q i L^{3, c}$, Xinbo Sun ${ }^{4, d}$ \\ ${ }^{1,2,3,4}$ School of Business Administration, Northeastern University,Shenyang, 110819,China \\ aemail:hqwang0628@126.com, bemail:neuglwu@126.com, email:hongseshitouliqi@163.com, \\ demail:xbsun@mail.neu.edu.cn
}

\begin{abstract}
Keywords: Higher education institution; Open courseware organization mechanism; Open courseware (OCW); Empirical study
\end{abstract}

\begin{abstract}
From the system perspective, this paper classifies the OCW organization mechanism into seven parts, which include course selection mechanism, teaching contents and methods design mechanism, video fabricating mechanism, intellectual property protection mechanism, service \& feedback mechanism, publicity \& promotion mechanism, and operation mechanism, aimed at constituting a structural equation model composed of such seven first-order factors. The first-order structural model is tenable, and there is higher correlation between factor constructs; the second-order factor model is also tenable and gives an interpretation of the correlation between the first-order factors. The research outcome will serve the China's higher education institutions.
\end{abstract}

\section{Introduction}

The rapid development of the Internet technology is pushing for a change in the traditional concept of education and style of learning. MIT initiated a worldwide open course sharing campaign, which brought new opportunities and challenges to higher education programs in 2000 . Currently, China is launching a new round of reform in teaching quality and teaching pattern among higher education institutions by offering free access to tens of millions of college curriculums. The study of open courses published on-line by prestigious universities at home and abroad is of historical and realistic significance to co-establishing and sharing high-quality teaching resources, thus avoiding low-level repetitions, as well as China's reform in higher education programs.

China's network education is different in many aspects with other countries, which we can see from OCW. For lack of literatures related to OCW organization mechanism at present, the following analysis of OCW and design of OCW organization mechanism will serve a significant reference.

\section{Theory Retrospection and Research Hypothesis}

Based on the study made by Pengjiao Wang et al.[1], and by reference to the discussion made by Shuai Ren [2], this paper puts forward such seven mechanisms as topic selection mechanism, teaching contents \& method design mechanism, video fabricating mechanism, intellectual property protection mechanism, service \& feedback mechanism, publicity \& promotion mechanism, and hypothesizes their correlation with organization mechanism.

\section{A. Course Selection Mechanism}

Network courses need to be developed selectively, because some courses are not suitable to be developed into network courses [3]. OCW can be developed better through investigating students' response[4].The topic selected as an elite OCW should have as large as possible over the discipline to which it belongs, to meet the increasing demand of a broad group of receivers for knowledge, 
and pay due attention to inter-disciplines, in an effort to achieve a balanced development[5,6]. Therefore, the selection mechanism plays a key role in organization mechanism. Hypotheses:

$\mathrm{H1}$ : the course selection mechanism is positively related to the OCW organization mechanism.

B. Teaching Contents and Methods Design Mechanism

Teaching contents include contents selection and contents organization, etc [5]; Distinct structure and contents of teaching, a classroom atmosphere contributed to learning, full exchanges between teachers and students, and diversified teaching methods, etc are the characteristics of a high-quality lesson. [7]. Advancing a common understanding of knowledge and effective exchanges during learning and teaching are both important [8]. Teaching methods should be adjusted on the feedback from students $[9,10]$. Therefore, the mechanism for design of teaching contents and methods affects the contents and quality of OCW, that is, appropriate teaching methods and contents will contribute to the expansion of OCW to a larger extent. Hypotheses:

$\mathrm{H} 2$ : the teaching contents and methods design mechanism are positively related to the OCW organization mechanism.

\section{Video Fabricating Mechanism}

The Ministry of Education released in 2011 Standards for Photographing and Fabricating of OCW, in which requirements for OCW suitable to China's higher education institutions in the matter of recording, fabricating, technical specifications and standardized filling-in of metadata are listed in detail [11]. The announcement of detailed requirements for the filling-in of metadata not only opens the door for users to access OCW easily, but contributes to an integrated management of on-line OCW, thus showing great significance to the development of OCW. A superior video fabricating can be ensured by a professional fabricating team, composition and quality of image, and sound, thus better serving sensory organs of receivers [5, 11]. Hypotheses:

H3: the video fabricating mechanism is positively related to the OCW organization mechanism.

D. Intellectual Property Protection Mechanism

The intellectual property protection mechanism means that pertinent rights and interests of intellectual property owners must be put under protection while developing OCW, thus arouse property owners' enthusiasm and realize the sustainable development of OCW. OCW can be managed and used effectively through multiple techniques such as setting video decoder's open comment and access control [12]. The implementation of collective copyright management seems to be a catholicon used for addressing the issue of network copyright authority. Hypotheses:

$\mathrm{H} 4$ : the intellectual property protection mechanism is positively related to the OCW organization mechanism.

\section{E. Service and Feedback Mechanism}

The OCW service mechanism means that the development of OCW should aim at offering good teaching service to broad receivers [13].The OCW service mechanism has not been established soundly in China at present - other materials and services remain to be improved except teaching video. The OCW feedback mechanism means using the comments and feedback from the mass to the OCW to further improve OCW. Hypotheses:

H5: the service and feedback mechanism is positively related to the OCW organization mechanism.

\section{F. Publicity and Promotion Mechanism}

By the publicity and promotion mechanism we can expand the work and promote it deeply [14]. The publicity and promotion of OCW serve not only as an important means for higher education institutions to promote themselves, but as an important strategy to achieve universalized higher 
education. With a number of China-leading OCW being developed freshly, how to publicize and promote it to public become urgent. Hypotheses:

H6: the publicity and promotion mechanism is positively related to the OCW organization mechanism.

\section{G. Operation Mechanism}

The operation mechanism refers to various strategies and supporting measures that push OCW to advance in a healthy and sustainable manner [6]. Without necessary financial support, the development of OCW will become impossible. At present, all the expenses used for the development of OCW in China are borne by the government or schools themselves, instead, OCW in foreign countries often attributes to the participation of non-government organizations supported by fund; Viewed from the long-term development, the operation mechanism of OCW needs to be adjusted in some ways. Hypotheses:

H7: the operation mechanism is positively related to the OCW organization mechanism.

\section{Research Design}

\section{A. Theoretical Model}

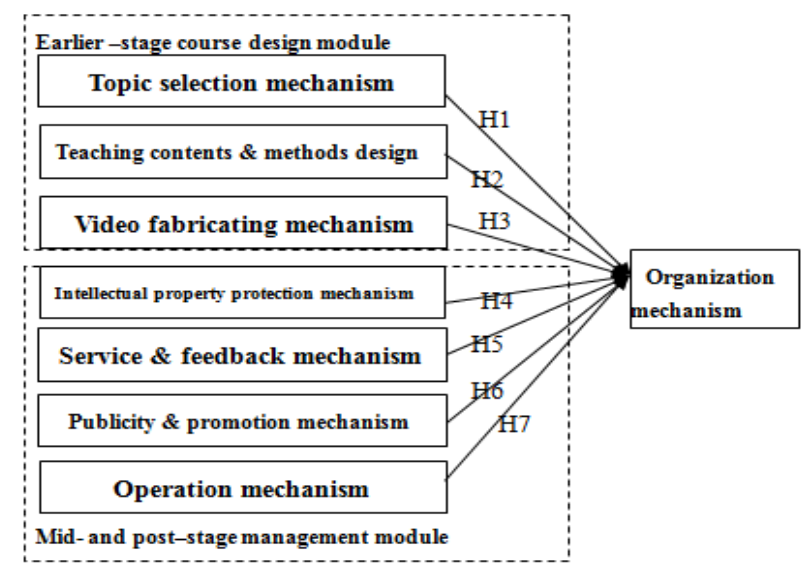

Fig.1. Theoretical model of the OCW organization mechanism

Based on the above analyses, the research framework of this paper is defined, as shown in Fig 1. In this paper, the research of the organization mechanism is conducted from such seven aspects as course selection mechanism, teaching contents \& methods design mechanism, video fabricating mechanism, intellectual property protection mechanism, service \& feedback mechanism, publicity \& promotion mechanism, and operation mechanism.

\section{B. Sample Selection \& Data Collection}

In this study, samples are selected from undergraduates, teachers, and other Internet users who often use the Internet. The diversity and discrepancy of samples avoid the limitation of research outcome, and thus make the research conclusion more applicable.

In this study, questionnaire is handed out on line via sojump.com,506 sheets of questionnaire are handed out and returned, of which 49 invalid sheets are rejected, thus the number of the valid questionnaire we finally obtained is 457 sheets, with a valid questionnaire return rate of $90.32 \%$. The survey was conducted from February March 2013.

The questionnaire consists of 4 parts: Part I: Purpose of the questionnaire; Part II: Concept and functions of OCW; Part III: Measuring tables for seven variables in the questionnaire, including 40 items; all the items are measured using Grade 5 Likert measuring table (1- very disagreed, 5very agreed); Part IV: Extend thanks to questionnaire participators. 


\section{Description of Variables}

1) Course selection mechanism: Based on the researches and analyses by P.J. Wang et al. on topic selection, we aim our survey at the effects of the course selection mechanism on the organization mechanism during the measurement. By referring to the existing literatures [5], this paper is designed with three items, which mainly involve the types of topics to be selected and analysis of user's needs.

2) Teaching Contents and Methods Design Mechanism: Based on the teaching contents and methods mentioned in Forbes and Morgan [16] this paper is designed with four items, including coverage and practicability of teaching contents, teaching activities and methods.

3) Video Fabricating Mechanism: Based on the researches by P.J. Wang[5,11] on matters that should be paid attention to during video fabricating, and pursuant to the Technical Standard for Photographing \& Fabricating of OCW published by the Ministry of Education, this paper is designed with five items relating to video fabricating mechanism. These items lay stress on video photographing and post processing respectively.

4) Intellectual Property Protection Mechanism: Based on the researches by S.A. Cassidy [12], the intellectual property relating to OCW, this paper is designed with four items relating to the intellectual property protection mechanism, including publicity and promotion of concept, coordinated effort with other organizations, establishment of a collective organization for literature management, development of an incentive mechanism.

5) Service \& Feedback Mechanism: Based on the researches [16,18], we aim our survey at the effects of the service and feedback mechanism. This paper is designed with five items, mainly involving the organization of a teaching assistant team, development of course website, expert assessment, teachers' feedback, and students' assessment, etc.

6) Publicity \& Promotion Mechanism: Based on the researches [17], This Publicity \& Promotion Mechanism is designed with three items, mainly involving publicity on sociable networks, publicity on TV \& press media, and application and development of mobile terminals.

7) Operation mechanism: Based on the researches by M.T. Sheng et al. into the OCW operation mechanism [6], this paper is designed with four items, which relate to what supports are needed for the sustainable development of OCW.

\section{Empircal Analysis}

\section{A. Reliability Analysis}

The reliability analysis for the measuring table using SPSS 19.0 indicates that the Cronbach's alpha of the whole measuring table is 0.901 , and the Cronbach's alpha of all variables and all their dimensions are larger than 0.8 , from the above result we conclude that the reliability of this measuring table is desirable.

\section{B. Validity Analysis}

Most of the measuring tables used in this study are mature measuring tables. The contents in the measuring tables had been partially amended through consulting experts in related fields and pre-survey, so that the questionnaire has a desirable content validity. The first-order confirmatory model analysis, in Amos 20.0 indicates that all the fitting indexes are within the range suggested by the structural equation model's fitting indexes. As shown in Table 1, most of fitting indexes are within the suggested range. Thus this model has a better goodness of fit, and is basically in line with the theoretical framework set forth in this paper.

C. Test of Hypothesis 
In this study, the seven organization mechanisms are of independent variables, the OCW organization mechanism is of a dependent variable in Amos 20.0, a1 g4 is of an observable variable, and $\mathrm{e} 1 \sim \mathrm{e} 30$ is of a residual variable.

We can see that the path1 coefficient is 0.776 ; the path2 coefficient is 0.837 ; the path3 coefficient is 0.866 ; the path4 coefficient is 0.943 ; the path 5 coefficient is 0.947 ; the path 6 coefficient is 0.806 ; the path7 coefficient is 0.885 . So $\mathrm{P}<0.001$ and all the hypotheses is confirmed.

\section{Main Research Outcomes and Implications}

This study relates to the analysis and test of OCW organization mechanism, and on the basis of preciously published literatures, puts forward the definitions of it, and suggests that they constitute an integral organization mechanism. The result indicates that hypotheses $\mathrm{H} 1 \sim \mathrm{H} 7$ are all tenable.

To put it concretely, the course selection mechanism is positively related with the organization mechanism, so variety of course types and accuracy of topic selection should be stressed.

Because the teaching contents \& methods design mechanism is positively related to the organization mechanism, the contents taught by teachers should lay stress on their comprehensiveness, practicality, logical lectures in an orderly and gradual manner, diversified and flexible teaching methods, interaction with student. The establishment of a perfect video fabricating mechanism will allow universities to spend more time in education itself.

We should spread education resources to maximize its value while protecting copyright. We need a definite copyright protection system. Definite instructions for admission will enable social power to play its role on the way to a more open education. We should organize an assistant team to guide after-class discussions, improve the course website and update the video. We should give play to the positive role of experts in assessing and recognizing OCW, and seek to obtain assessment and feedback from students and teachers and the mass. We also should develop applications suitable to mobile terminals to spread OCW. At last, donations from individuals and businesses in addition to expenses provided by the government should be sought to maintain the development of OCW.

There exist some limitations in this paper, e.g. some other criterions may be adopted by experts to evaluate the elite OCW, however, the organization mechanism set forth in this paper is just applicable to the development of mass-level OCW. Following this, we will carry out a study aiming at the factors affecting state-level elite OCW.

\section{Acknowledgment}

This paper is funded by "2012 Liaoning Ordinary Higher Learning - Undergraduate Course Teaching Reform Research Grogram and 2012 Northeastern University Ordinary Higher Learning Undergraduate Course Teaching Reform Research Grogram”.

TABLE I FIT INDICES OF CONFIRMATORY FACTOR ANALYSIS

\begin{tabular}{|l|l|l|l|l|l|l|l|l|}
\hline \multirow{2}{*}{ Test statistic } & \multicolumn{4}{|l|}{ Absolute fit index } & \multicolumn{3}{l|}{ Relative fit index } \\
\cline { 2 - 9 } & CMIN/DF & GFI & RMR & RMSEA & IFI & NFI & CFI & TLI \\
\hline Actual outcome & $\mathbf{1 . 6 8 8}$ & $\mathbf{0 . 9 0 7}$ & $\mathbf{0 . 0 2 1}$ & $\mathbf{0 . 0 3 9}$ & $\mathbf{0 . 9 1 3}$ & $\mathbf{0 . 8 1 0}$ & $\mathbf{0 . 9 1 2}$ & $\mathbf{0 . 9 0 3}$ \\
\hline Suggested range & $<2$ & $>\mathbf{0 . 9}$ & $<\mathbf{0 . 0 5}$ & $<\mathbf{0 . 0 5}$ & $>\mathbf{0 . 9}$ & $>\mathbf{0 . 9}$ & $>\mathbf{0 . 9}$ & $>\mathbf{0 . 9}$ \\
\hline
\end{tabular}




\section{References}

[1] P.J. Wang, J. L Tian, Q. Jiang. Study of Problems in Developing Elite Open Courseware for Higher Education Institutions and Countermeasures[J]. Education with Electrical Audio-visual Aids in China,2012,(11),86 92,

[2] S. Ren. Open Courseware-A Change in Learning Style[J]. China Education Network, 2013(3),55 58,

[3] K.L. Meaning of Network Course and its Teaching Design. [J] China Tele-education, 2006(9). 46 49,

[4]Ed Hahn.Video lectures help enhance online information literacy course[J].Reference Services Review, 2012,40(1),49 59

[5] P.J. Wang, X. Jin, L. Lin. Strategic Study of China's on-line Open Courseware Topic Selection and Contents Design[J]. Modern Tele-Education, 2012(6),48 54

[6] M.T. Sheng, X.L. Dai, P.J. Wang. Study on Developing Elite Resources Sharing Courses in a Sustainable Way[J]. China Technical Equipment for Education, 2012(30),7 12

[7] H. Meyer. What's the Best Teaching? [M] Shanghai: East China Normal University Press, 2011,9 10

[8]J.R. Hill, M.J. Hannafin.Teaching and Learning in Digital Environments: The Resurgence of Resource-Based Learning[J]. ETR \& D, 2001,49(3),37 52

[9]J.P.T. Fatt, A Method for Trainers to Examine Teaching Feedback[J], Management Research News Vol. 26. No.1, pp44 45, 2003.

[10]Y.K. Zhang, Y.M. Mei. To Develop Elite Courses Vigorously Concentrating on Quality[J]. Teaching of Chinese Universities, 2004(9), 13 14,

[11]P.J. Wang, J.L. Wang, Q. Jiang. Study of Problems in Developing Elite Open Courseware for Higher Education Institutions and Countermeasures[J]. Education with Electrical Audio-visual Aids in China, 2012(11),86 92

[12]S.A. Cassidy, An Analysis of VPB, a New Video Codec for the Web[D]. Rochester Institute of Technology Rochester. NY November, 2011.

[13]Q. He. How to Win More Applauds and Draw a Large Audience for Open Courseware[J]. Shanghai Education, 2001(24),54 55.

[14]J.C. Simon, K.S. Soliman. An alternative method to measure MIS faculty teaching performance[J]. International Journal of Educational Management , 2003,17(5), 159 199,

[15]C.L. Morgan. An Inquiry Into Situational Interest In a Tenth Grade History Class: Lesson Design And Implementation From Berlyne And Bergin Perspective[D]. Detroit Michigan: Wayne State University, 2010

[16]J. Wang, C. Zeng, L. Lin. Implications of Successful Foreign Open Courseware Cases for China[J]. Chinese IT Education, 2011(24),65 69

[17]H. Luo, Y.H. Bian, Y.P. Wang. An Analysis on Open Courseware[J]. Chinese Medical Education Technology, 2012(8), 407 409

[18]J.Wang, Y. He. Analysis of the Fabricating Technique and Classroom Behaviors for Harvard on-line Open Courses[J]. Modern Tele-Education, 2011(5),71 76 